\title{
Generality of Correlation between Yield and Reduced Mass of Raw Materials in Organic Reactions
}

\author{
Masatoshi Kawashima \\ Laboratory Section, Azuma Co., Ltd. \\ 1-6-13 Tamasaki-Nishi, Ichihara, Chiba 290-0044 \\ E-mail: kawashima@azuma-g.co.jp
}

To validate a generality of the correlation between product yield and reduced mass of raw materials, the regression analysis of 129 reaction examples (55 as a sample size) including at least 66 types of reactions used in syntheses of natural products such as peptides and terpenes was conducted. It was possible to predict a yield of a variety of synthetic reactions for a synthesis of natural product with many aliphatic carbon chains by applying a reduced mass, adjusted with a molecular weight and the number of rotatable bond, to the regression equation. Moreover, it was found that the increase in yield due to a use of the adjusted reduced mass correlated with the harmonic mean of the molar heat capacity of raw materials and was expressed as a second-order approximation within the analysis range.

\section{Keywords: Yield |Reduced Mass |Correlation |Prediction}

The author has reported the correlation between yield and reduced mass of raw materials in intermolecular/intramolecular coupling reactions, cyclization reactions, and reactions of fullerene. ${ }^{1,2,3}$ The same regression equation (1),

$$
\text { yield }=-0.186 M_{\mathrm{AB}} / n+100
$$

where $M_{\mathrm{AB}}$ is the reduced mass per mole, $n=n_{\mathrm{A}} n_{\mathrm{B}} n_{\mathrm{I}}, n_{\mathrm{A}}$ and $n_{\mathrm{B}}$ are the total number of each reaction site in molecular $\mathrm{A}$ and molecular $\mathrm{B}$, respectively, and $n_{\mathrm{I}}$ is the number to distinguish whether it is an intramolecular reaction or intermolecular reaction, was held in the reactions. Reactions selected for the analysis were chiefly metal-catalyzed cross coupling reactions, cycloadditions, and Bingel reaction. Therefore, to find out about other types of reactions, papers on the synthesis of several natural products were selected and analyzed in this report.

First, a part of reactions used in a total synthesis of Antillatoxin shown in Scheme 1 was analyzed by using equation (1). ${ }^{4}$ In the case of intramolecular reaction, $M_{\mathrm{B}}$ was set to be the same as $M_{\mathrm{A}}$, the variable $n_{\mathrm{A}}$ and $n_{\mathrm{B}}$ was set to the same value, and the variable $n_{\mathrm{I}}$ was set to 2 as previous reports. ${ }^{2,3}$ In a previous report, when a molecular weight of a product exceeded about 1500 , the mass according to the number of rotatable bonds (NORB) of the raw material was subtracted from the molecular weight and an adjusted reduced mass $\left(M_{\mathrm{AB}}^{\prime}\right)$ was obtained from the adjusted molecular weight $\left(M_{\mathrm{A}(\mathrm{B})}^{\prime}\right){ }^{3,5}$ In this report, to further improve the accuracy, the mass according to NORB $\left(R_{\mathrm{A}(\mathrm{B})}\right)$ was adjusted according to $M_{\mathrm{A}(\mathrm{B})}$, and subtracted from $M_{\mathrm{A}(\mathrm{B})}$ to obtain $M_{\mathrm{A}(\mathrm{B})}^{\prime}$ as shown in (3). Then, $M_{\mathrm{AB}}^{\prime}$ was obtained from $M_{\mathrm{A}}^{\prime}$ and $M_{\mathrm{B}}^{\prime}$ as presented in (2) and was used in (1). The coefficient of 14.03 in (3) is the mass of the methylene chain, which is often a cause of

$$
\begin{aligned}
& \text { yield }=-0.186 \frac{M_{\mathrm{AB}}^{\prime}}{n}+100 \\
& M_{\mathrm{AB}}^{\prime}=\frac{M_{\mathrm{A}}^{\prime} M_{\mathrm{B}}^{\prime}}{M_{\mathrm{A}}^{\prime}+M_{\mathrm{B}}^{\prime}} \\
& M_{\mathrm{A}(\mathrm{B})}^{\prime}=M_{\mathrm{A}(\mathrm{B})}-14.03 a R_{A(B)} \\
& a=0.00177 M_{\mathrm{A}(\mathrm{B})} \quad\left(M_{A(B)} \leq 768\right) \\
& a=1.36 \quad\left(M_{\mathrm{A}(\mathrm{B})}>768\right)
\end{aligned}
$$

a rotatable bond. For a case of a reaction using condensation reagent for esterification or amidation, the intermediate involved in the rate-determining step was also considered for analysis. An analysis was conducted as shown in Table 1 and resulted in a regression coefficient of 1.29 and a coefficient of determination of 0.94 . Literature versus predicted yields plot is included in Figure 1(a) as a regression through the origin (RTO) model and expressed as blue circle.
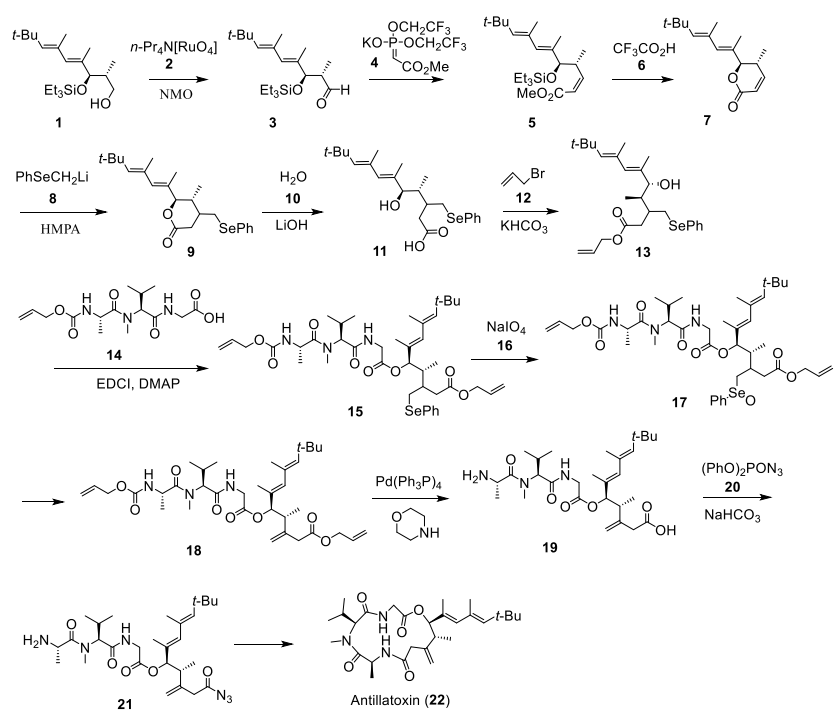

Scheme 1. Reaction scheme for an analysis of reactions used in a total synthesis of Antillatoxin, HMPA = hexamethylphosphoramide, $\mathrm{EDCl}=1$-(3-dimethylaminopropyl)-3ethylcarbodiimide hydrochloride, DMAP = 4-dimethylaminopyridine .

Second, reactions used in a synthesis of a fragment for a total synthesis of Microcyctin-LF depicted in Scheme 2 was analyzed. ${ }^{6}$ An analysis was conducted as shown in Table 2 . The predicted yields are in close agreement with the literature yield to result in a regression coefficient of 1.10 and a coefficient of determination of 0.99 . Literature versus predicted yields plot is included in Figure 1(a) and expressed as red rhombus. 
Table 1. An analysis of reactions used in a synthesis of a part of a total synthesis of Antillatoxin.

\begin{tabular}{ccrrrrrrrrrr}
\hline $\mathrm{A}$ & $\mathrm{B}$ & $M_{\mathrm{A}}{ }^{\mathrm{a}}$ & $M_{\mathrm{B}}{ }^{\mathrm{b}}$ & $M_{\mathrm{AB}}{ }^{\mathrm{c}}$ & $n_{\mathrm{A}}{ }^{\mathrm{d}}$ & $n_{\mathrm{B}}{ }^{\mathrm{e}}$ & $n_{\mathrm{I}}{ }^{\mathrm{f}}$ & $n^{\mathrm{g}}$ & $Y_{\text {lit. }}{ }^{\mathrm{h}}$ & $Y_{\text {int. }}{ }^{\mathrm{i}}$ & $Y_{\text {pred. }}{ }^{\mathrm{j}}$ \\
\hline $\mathbf{1}$ & $\mathbf{2}$ & 341 & 351 & 132 & 1 & 1 & 1 & 1 & & 75 & \\
$\mathbf{3}$ & $\mathbf{4}$ & 339 & 356 & 138 & 1 & 1 & 1 & 1 & & 74 & \\
$\mathbf{5}$ & $\mathbf{6}$ & 395 & 114 & 77 & 1 & 1 & 1 & 1 & 52 & 86 & 48 \\
\hline $\mathbf{7}$ & $\mathbf{8}$ & 248 & 177 & 91 & 1 & 1 & 1 & 1 & 50 & 83 & 83 \\
\hline $\mathbf{9}$ & $\mathbf{1 0}$ & 419 & 18 & 17 & 1 & 1 & 1 & 1 & & 97 & \\
$\mathbf{1 1}$ & $\mathbf{1 2}$ & 437 & 121 & 85 & 1 & 1 & 1 & 1 & & 84 & \\
$\mathbf{1 3}$ & $\mathbf{1 4}$ & 478 & 500 & 146 & 1 & 1 & 1 & 1 & 34 & 73 & 59 \\
\hline $\mathbf{1 5}$ & $\mathbf{1 6}$ & 803 & 214 & 129 & 1 & 1 & 1 & 1 & 67 & 76 & 76 \\
\hline $\mathbf{1 7}$ & $\mathbf{1 7}$ & 819 & 819 & 163 & 1 & 1 & 2 & 2 & & 85 & \\
$\mathbf{1 8}$ & $\mathbf{1 8}$ & 646 & 646 & 146 & 1 & 1 & 2 & 2 & & 86 & \\
$\mathbf{1 9}$ & $\mathbf{2 0}$ & 522 & 275 & 134 & 1 & 1 & 1 & 1 & & 75 & \\
$\mathbf{2 1}$ & $\mathbf{2 1}$ & 547 & 547 & 158 & 1 & 1 & 2 & 2 & 29 & 85 & 47 \\
\hline
\end{tabular}

${ }^{a}$ molecular weight of molecule A. ${ }^{b}$ molecular weight of molecule B. ${ }^{c}$ adjusted reduced mass. ${ }^{\mathrm{d}}$ number of reaction sites of molecule A. ${ }^{\mathrm{e}}$ number of reaction sites of molecule B. ${ }^{\text {intermolecular reaction }}=1$, intramolecular reaction $=2$. ${ }^{\mathrm{g}} n=n_{\mathrm{A}} n_{\mathrm{B}} n_{\mathrm{I}}$. ${ }^{\mathrm{h}}$ literature yield. ${ }^{\mathrm{i}}$ predicted yield of intermediate in each step. ${ }^{j}$ predicted yield.

(a)

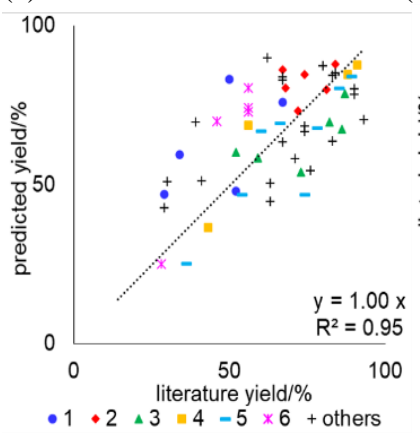

(b)

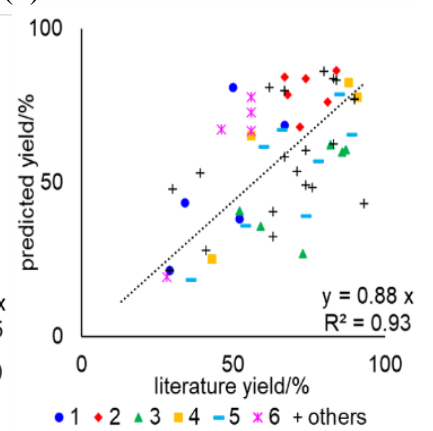

Figure 1. Literature versus predicted yields plot of the reactions used in the synthesis of natural products; 1 : data of Table 1, 2: data of Table2, $\triangle 3$ :data of Table 3, 4: data of Table4, -5: data of Table5, $*$ : data of Table 6, +: data of others. (a) calculated by using $M_{\mathrm{AB}}^{\prime}$. (b) calculated by using $M_{\mathrm{AB}}$.

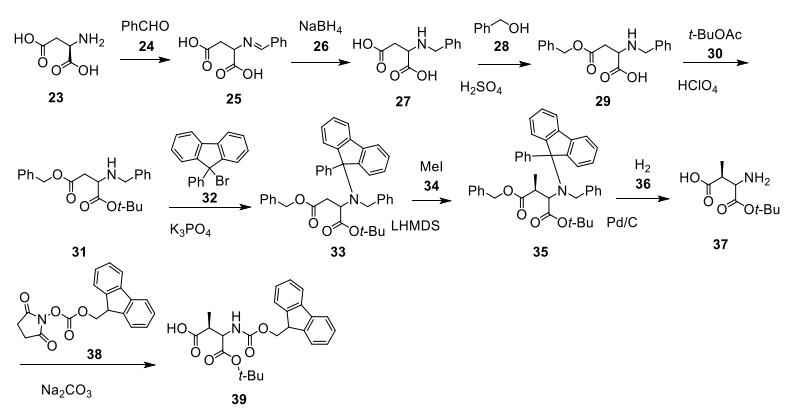

Scheme 2. Reaction scheme for an analysis of reactions used in a synthesis of a fragment for a total synthesis of Microcyctin$\mathrm{LF}, \mathrm{Ac}=$ acetyl.

Third, reactions used in a synthesis of a part of a total synthesis of mozamide A shown in Scheme 3 was analyzed. ${ }^{7}$ An analysis was carried out as shown in Table 3 . The predicted yields are lower than the literature yields, and a regression coefficients $(0.87)$ are somewhat smaller, but a coefficient of determination (0.98) is larger. Literature versus predicted yields plot is included in Figure 1(a) and expressed as green triangle.
Table 2. An analysis of reactions used in a synthesis of a fragment for Microcyctin-LF.

\begin{tabular}{ccrrrrrrrrrr}
\hline $\mathrm{A}$ & $\mathrm{B}$ & $M_{\mathrm{A}}{ }^{\mathrm{a}}$ & $M_{\mathrm{B}}{ }^{\mathrm{b}}$ & $M_{\mathrm{AB}}{ }^{\mathrm{c}}$ & $n_{\mathrm{A}}{ }^{\mathrm{d}}$ & $n_{\mathrm{B}}{ }^{\mathrm{e}}$ & $n_{\mathrm{I}}{ }^{\mathrm{f}}$ & $n^{\mathrm{g}}$ & $Y_{\text {lit. }}{ }^{\mathrm{h}}$ & $Y_{\text {int. }}{ }^{\mathrm{i}}$ & $Y_{\text {pred. }}{ }^{\mathrm{j}}$ \\
\hline $\mathbf{2 3}$ & $\mathbf{2 4}$ & 133 & 106 & 54 & 1 & 1 & 1 & 1 & & 90 & \\
$\mathbf{2 5}$ & $\mathbf{2 6}$ & 221 & 38 & 31 & 1 & 1 & 1 & 1 & 74 & 94 & 85 \\
\hline $\mathbf{2 7}$ & $\mathbf{2 8}$ & 223 & 108 & 65 & 1 & 1 & 1 & 1 & 84 & 88 & 88 \\
\hline $\mathbf{2 9}$ & $\mathbf{3 0}$ & 313 & 116 & 75 & 1 & 1 & 1 & 1 & 67 & 86 & 86 \\
\hline $\mathbf{3 1}$ & $\mathbf{3 2}$ & 369 & 321 & 145 & 1 & 1 & 1 & 1 & 72 & 73 & 73 \\
\hline $\mathbf{3 3}$ & $\mathbf{3 4}$ & 610 & 142 & 106 & 1 & 1 & 1 & 1 & 68 & 80 & 80 \\
\hline $\mathbf{3 7}$ & $\mathbf{3 6}$ & 624 & 2 & 2 & 1 & 1 & 1 & 1 & & 100 & \\
\hline
\end{tabular}

${ }^{a}$ molecular weight of molecule A. ${ }^{b}$ molecular weight of molecule B. cadjusted reduced mass. ${ }^{\mathrm{d}}$ number of reaction sites of molecule A. ${ }^{\mathrm{e}}$ number of reaction sites of molecule $\mathrm{B}$. fintermolecular reaction $=1$, intramolecular reaction $=2 .{ }^{\mathrm{g}} n=n_{\mathrm{A}} n_{\mathrm{B}} n_{\mathrm{I}} .{ }^{\mathrm{h}}$ literature yield. ${ }^{\mathrm{i}}$ predicted yield of intermediate in each step. ${ }^{\mathrm{j}}$ predicted yield.

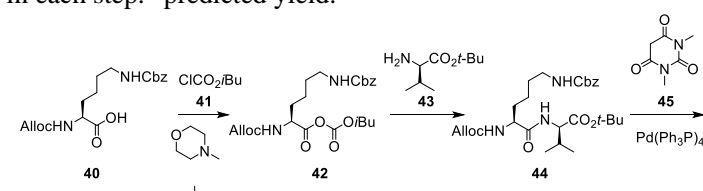
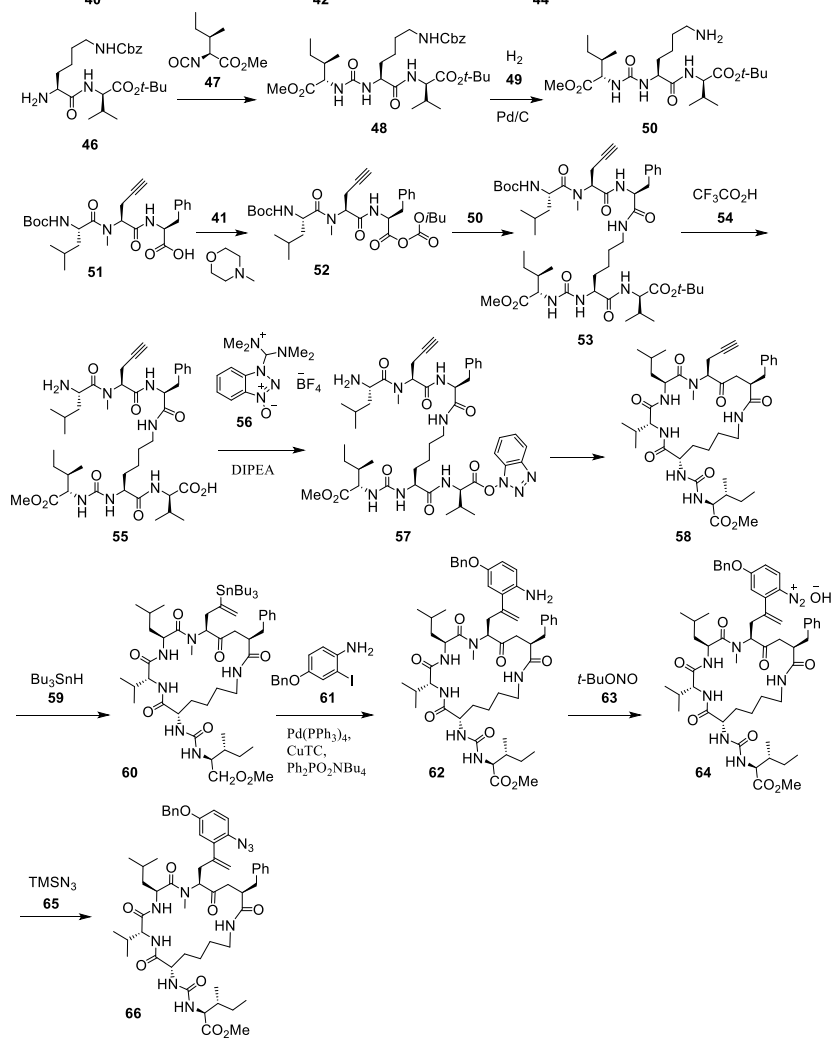

Scheme 3. Reaction scheme for an analysis of reactions used in a synthesis of a part of a total synthesis of mozamide A, Alloc $=$ allyloxycarbonyl, $\mathrm{Cbz}=$ benzyloxycarbonyl, DIPEA = diisopropylethylamine, CuTC = copper(I) thiophene-2-carboxylate, TMS $=$ trimethylsilyl.

Fourth, reactions used in a synthesis of a part of total synthesis of (+)-leucosceptroid B shown in Scheme 4 was analyzed. ${ }^{8}$ An analysis was conducted as shown in Table 4 . The predicted and literature yields were in good agreement, resulting in a regression coefficient of 0.99 and a coefficient of determination of 0.99 . Literature versus predicted yields plot is included in Figure 1(a) and expressed as orange square.

Fifth, the reactions used in total synthesis of (+)leucosceptroid B and (+)-leucosceptroid A shown in 
Table 3. An analysis of reactions used in a synthesis of a part of a total synthesis of mozamide A.

\begin{tabular}{rrrrrrrrrrrrr}
\hline $\mathrm{A}$ & $\mathrm{B}$ & \multicolumn{1}{c}{$M_{\mathrm{A}}{ }^{\mathrm{a}}$} & $M_{\mathrm{B}}{ }^{\mathrm{b}}$ & $M_{\mathrm{AB}}{ }^{\mathrm{c}}$ & $n_{\mathrm{A}}{ }^{\mathrm{d}}$ & $n_{\mathrm{B}}{ }^{\mathrm{e}}$ & $n_{\mathrm{I}}^{\mathrm{f}}$ & $n^{\mathrm{g}}$ & $Y_{\text {lit. }}{ }^{\mathrm{h}}$ & $Y_{\text {int. }}{ }^{\mathrm{i}}$ & $Y_{\text {pred. }}{ }^{\mathrm{j}}$ \\
\hline $\mathbf{4 0}$ & $\mathbf{4 1}$ & 364 & 137 & 83 & 1 & 1 & 1 & 1 & & 85 & \\
$\mathbf{4 2}$ & $\mathbf{4 3}$ & 465 & 173 & 95 & 1 & 1 & 1 & 1 & 82 & 82 & 70 \\
\hline $\mathbf{4 4}$ & $\mathbf{4 5}$ & 520 & 156 & 98 & 1 & 1 & 1 & 1 & & 82 & \\
$\mathbf{4 6}$ & $\mathbf{4 7}$ & 436 & 171 & 95 & 1 & 1 & 1 & 1 & 86 & 82 & 67 \\
\hline $\mathbf{4 8}$ & $\mathbf{4 9}$ & 607 & 2 & 2 & 1 & 1 & 1 & 1 & & 100 & \\
$\mathbf{5 1}$ & $\mathbf{4 1}$ & 488 & 137 & 90 & 1 & 1 & 1 & 1 & & 83 & \\
$\mathbf{5 2}$ & $\mathbf{5 0}$ & 588 & 473 & 148 & 1 & 1 & 1 & 1 & 52 & 73 & 60 \\
\hline $\mathbf{5 3}$ & $\mathbf{5 4}$ & 942 & 114 & 83 & 1 & 1 & 1 & 1 & & 85 & \\
$\mathbf{5 5}$ & $\mathbf{5 6}$ & 786 & 321 & 130 & 1 & 1 & 1 & 1 & & 76 & \\
$\mathbf{5 7}$ & $\mathbf{5 7}$ & 903 & 903 & 168 & 1 & 1 & 2 & 2 & 73 & 84 & 54 \\
\hline $\mathbf{5 8}$ & $\mathbf{5 9}$ & 767 & 291 & 115 & 1 & 1 & 1 & 1 & 87 & 79 & 79 \\
\hline $\mathbf{6 0}$ & $\mathbf{6 1}$ & 1060 & 325 & 160 & 1 & 1 & 1 & 1 & & 70 & \\
$\mathbf{6 2}$ & $\mathbf{6 3}$ & 966 & 103 & 75 & 1 & 1 & 1 & 1 & & 86 & \\
$\mathbf{6 4}$ & $\mathbf{6 5}$ & 978 & 115 & 17 & 1 & 1 & 1 & 1 & 59 & 97 & 59 \\
\hline
\end{tabular}

amolecular weight of molecule A. ${ }^{b}$ molecular weight of molecule B. ${ }^{c}$ adjusted reduced mass. ${ }^{d}$ number of reaction sites of molecule A. ${ }^{\mathrm{e}}$ number

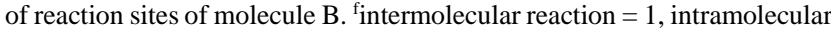
reaction $=2 .{ }^{\mathrm{g}} n=n_{\mathrm{A}} n_{\mathrm{B}} n_{\mathrm{I}}$. ${ }^{\text {h }}$ literature yield. ${ }^{\mathrm{i}}$ predicted yield of intermediate in each step. ${ }^{\mathrm{j}}$ predicted yield.
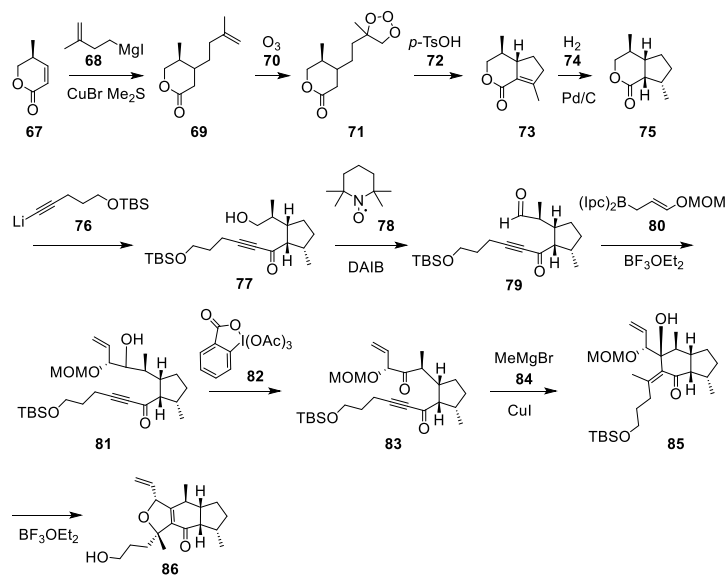

Scheme 4. Reaction scheme for an analysis of reactions used in a synthesis of a part of a total synthesis of (+)-leucosceptroid $\mathrm{B}, p-\mathrm{TsOH}=p$-toluenesulfonic acid, TBS $=$ tert-butyldimethylsilyl, DAIB $=$ (diacetoxyiodo)benzene, $\mathrm{MOM}=$ methoxymethyl, $\mathrm{ipc}=$ isopinocamphenyl.

Table 4. An analysis of reactions used in a part of a total synthesis of (+)-leucosceptroid B.

\begin{tabular}{ccccccccccccc}
$\mathrm{A}$ & $\mathrm{B}$ & $M_{\mathrm{A}}{ }^{\mathrm{a}}$ & $M_{\mathrm{B}}{ }^{\mathrm{b}}$ & $M_{\mathrm{AB}}{ }^{\mathrm{c}}$ & $n_{\mathrm{A}}{ }^{\mathrm{d}}$ & $n_{\mathrm{B}}{ }^{\mathrm{e}}$ & $n_{\mathrm{I}}{ }^{\mathrm{f}}$ & $n^{\mathrm{g}}$ & $Y_{\text {lit. }}{ }^{\mathrm{h}}$ & $Y_{\text {int. }}{ }^{\mathrm{i}}$ & $Y_{\text {pred. }}{ }^{\mathrm{j}}$ \\
\hline $\mathbf{6 7}$ & $\mathbf{6 8}$ & 112 & 220 & 66 & 1 & 1 & 1 & 1 & & 88 & \\
$\mathbf{6 9}$ & $\mathbf{7 0}$ & 182 & 48 & 36 & 1 & 1 & 1 & 1 & & 93 & \\
$\mathbf{7 1}$ & $\mathbf{7 2}$ & 230 & 172 & 85 & 1 & 1 & 1 & 1 & & 84 & \\
$\mathbf{7 3}$ & $\mathbf{7 4}$ & 166 & 2 & 2 & 1 & 1 & 1 & 1 & 56 & 100 & 69 \\
\hline $\mathbf{7 5}$ & $\mathbf{7 6}$ & 168 & 204 & 81 & 1 & 1 & 1 & 1 & & 85 & \\
$\mathbf{7 7}$ & $\mathbf{7 8}$ & 367 & 156 & 89 & 1 & 1 & 1 & 1 & & 84 & \\
$\mathbf{7 9}$ & $\mathbf{8 0}$ & 365 & 386 & 147 & 1 & 1 & 1 & 1 & & 73 & \\
$\mathbf{8 1}$ & $\mathbf{8 2}$ & 467 & 424 & 158 & 1 & 1 & 1 & 1 & 43 & 71 & 36 \\
\hline $\mathbf{8 3}$ & $\mathbf{8 4}$ & 465 & 119 & 83 & 1 & 1 & 1 & 1 & 88 & 85 & 85 \\
\hline $\mathbf{8 5}$ & $\mathbf{8 5}$ & 481 & 481 & 133 & 1 & 1 & 2 & 2 & 91 & 88 & 88 \\
\hline
\end{tabular}

${ }^{a}$ molecular weight of molecule A. ${ }^{b}$ molecular weight of molecule B. ${ }^{\mathrm{c}}$ adjusted reduced mass. ${ }^{\mathrm{d}}$ number of reaction sites of molecule A. ${ }^{\mathrm{e}}$ number

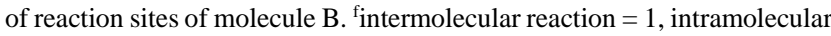

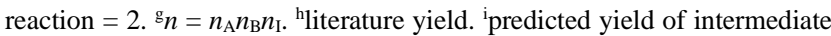
in each step. ${ }^{\mathrm{j}}$ predicted yield.

Scheme 5 was analyzed. ${ }^{9}$ An analysis was conducted as expressed in Table 5. The predicted and literature yields were in relatively good agreement, resulting in a regression coefficient of 0.90 and a coefficient of determination of 0.98 . Literature versus predicted yields plot is included in Figure 1(a) and expressed as light blue minus.

Sixth, reactions used in a total synthesis of (-)-6-epiophiobolin $\mathrm{N}$ shown in Scheme 6 was analyzed. ${ }^{10}$ An analysis was carried out as shown in Table 6. Although the predicted yields had higher than the literature yield (a regression coefficient $=1.35$ ), a coefficient of determination was very large (0.99). Literature versus predicted yields plot is included in Figure 1(a) and expressed as pink asterisk.

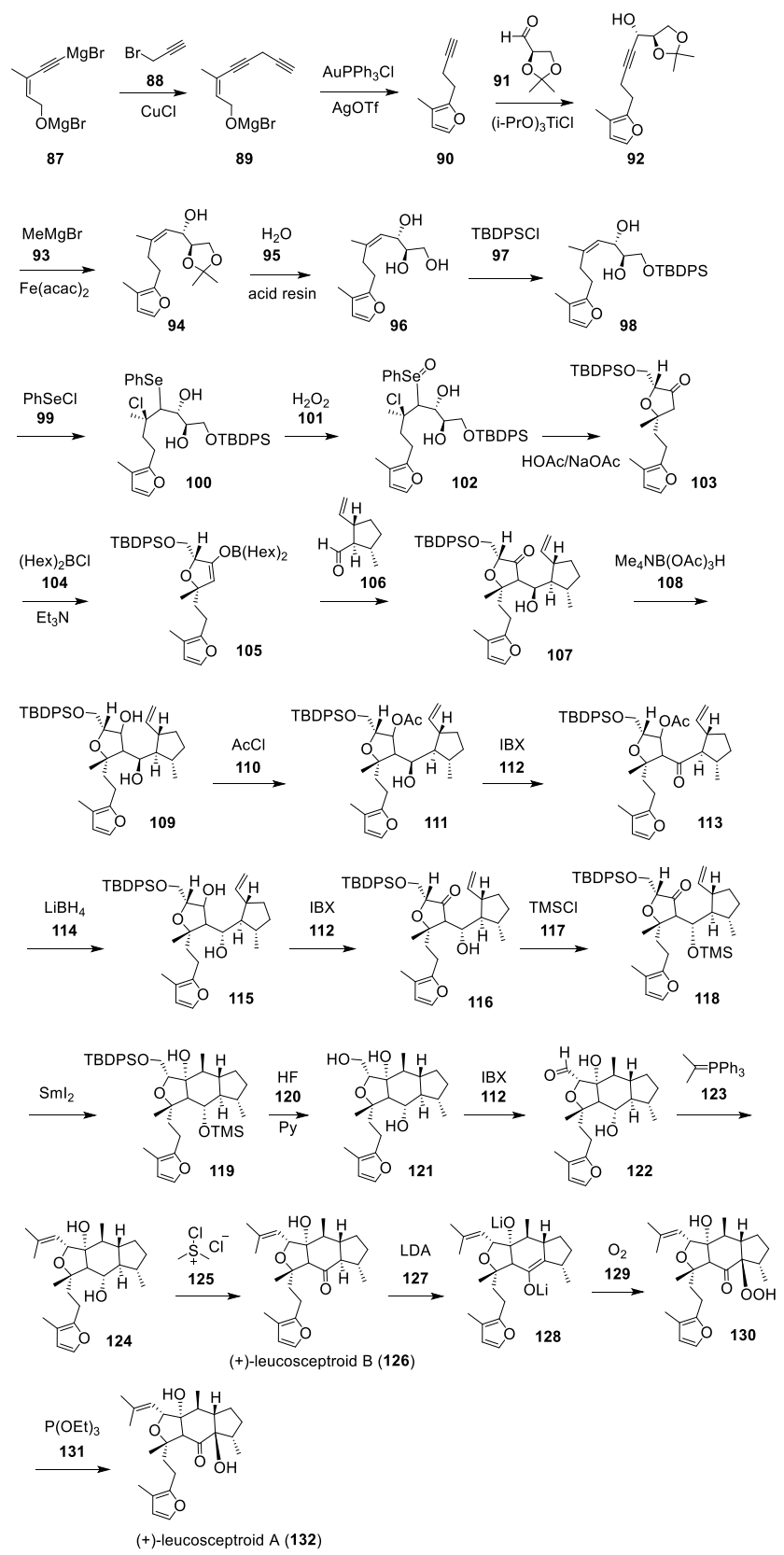

Scheme 5. Reaction scheme for an analysis of reactions used in a total synthesis of (+)-leucosceptroid B and (+)leucosceptroid A, TBDPS = tert-butyldiphenylsilyl, Ac = acetyl, IBX = 2-iodoxybenzoic acid, TMS = trimethylsilyl, $\mathrm{LDA}=$ lithium diisopropylamide. 
Finally, analysis of reactions used in a synthesis of $(-)$ alotaketal C, (-)-alotaketal D, (+)-luffarin I, (+)-luffarin A, (-)nitidasin, and four fragments that differ from the fragment of Microcyctin-LF described above were conducted as the same manner as described above and were included in Figure 1(a), and expressed as black plus. ${ }^{6,11,12,13}$ The data shown in Figure 1(a) are after outliers by Smirnov-Grubbs test as a significance level of 0.05. Looking at the color-coded plots in Figure 1(a), we can see that the relationship between literature and predicted yields is characteristic of each literature. In other words, there are three types of plots: those $(\bullet, \bullet, *)$ that are clustered on the upper side of the regression line, those $(\Delta)$ that clustered on the lower side of the regression line, and those $(\square,-)$ that are relatively well aligned with the regression line. There is no significant difference in the type of reaction used in each synthesis, suggesting that one of the reasons for this is that the purification efficiency or purities differ for each literature. The regression line summarizing the all results of the above analyses is also shown in Figure 1(a) as a dotted line. A regression coefficient and a determination coefficient were 1.00 and 0.95 , respectively. Figure 1 (b) shows a result obtained by using $M_{\mathrm{AB}}$ calculated without adjusting $M_{\mathrm{A}(\mathrm{B})}$ by NORB. The effect of an adjustment by NORB is evident from difference in these regression coefficients and difference in coefficients of determination. A significant relationship between harmonic mean of molar heat capacity $(C p)$ of raw materials and an increase in a yield calculated using $M_{\mathrm{AB}}^{\prime}$ compared to a yield calculated using $M_{\mathrm{AB}}$ was obtained using data of Tables 4 and 5 and is presented in Figure $2 .{ }^{14}$ The correlation was expressed as a quadratic approximation within the analysis range, and a high coefficient of determination was observed $\left(R^{2}=0.94\right)$;

$$
y=11.2 C p_{\mathrm{AB}}^{2}+11.9 C p_{\mathrm{AB}}-0.5,
$$

where $y$ is an increase in yield due to an adjustment by NORB, $C p_{\mathrm{AB}}$ is the harmonic mean of molar heat capacity of raw materials. Although a sample size for each reaction type used in the analysis was small, high correlation was observed throughout despite a large number of reaction types. Moreover, the fact that the regression equation for the correlation between yield and reduced mass, which held in C-C, C-N, C-O couplings, cycloadditions, and Bingel reactions, is valid for the present analysis indicates high generality as a regression equation for yield prediction in thermal organic reactions. ${ }^{1,2,3}$ This equation can be applied when the reaction conditions are appropriate. If the reaction conditions are optimized but deviate significantly from the regression equation, it may be because the molecular weight of the chemical species involved in the reaction or the reaction mechanism is different from what is assumed.

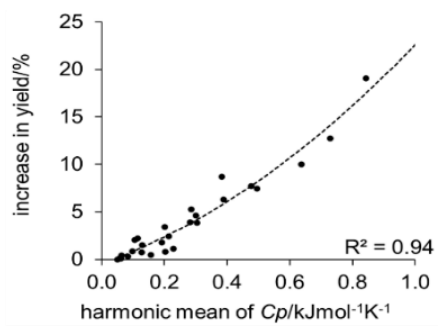

Figure 2. Relationship between a harmonic mean of $C p$ of raw materials and an increase in yield due to an adjustment by NORB.
Table 5. An analysis of reactions used in a total synthesis of (+)-leucosceptroid B and (+)-leucosceptroid A.

\begin{tabular}{cccccccccccc}
\hline $\mathrm{A}$ & $\mathrm{B}$ & $M_{\mathrm{A}}{ }^{\mathrm{a}}$ & $M_{\mathrm{B}}{ }^{\mathrm{b}}$ & $M_{\mathrm{AB}}{ }^{\mathrm{c}}$ & $n_{\mathrm{A}}{ }^{\mathrm{d}}$ & $n_{\mathrm{B}}{ }^{\mathrm{e}}$ & $n_{\mathrm{I}}^{\mathrm{f}}$ & $n^{\mathrm{g}}$ & $Y_{\text {lit. }}{ }^{\mathrm{h}}$ & $Y_{\text {int. }}{ }^{\mathrm{i}}$ & $Y_{\text {pred. }}{ }^{\mathrm{j}}$ \\
\hline $\mathbf{8 7}$ & $\mathbf{8 8}$ & 303 & 119 & 81 & 1 & 1 & 1 & 1 & & 85 & \\
$\mathbf{8 9}$ & $\mathbf{8 9}$ & 134 & 134 & 59 & 1 & 1 & 2 & 2 & 85 & 95 & 80 \\
\hline $\mathbf{9 0}$ & $\mathbf{9 1}$ & 134 & 130 & 64 & 1 & 1 & 1 & 1 & & 88 & \\
$\mathbf{9 2}$ & $\mathbf{9 3}$ & 264 & 238 & 114 & 1 & 1 & 1 & 1 & 66 & 79 & 69 \\
\hline $\mathbf{9 4}$ & $\mathbf{9 5}$ & 280 & 18 & 16 & 1 & 1 & 1 & 1 & & 97 & \\
$\mathbf{9 6}$ & $\mathbf{9 7}$ & 240 & 275 & 108 & 1 & 1 & 1 & 1 & & 80 & \\
$\mathbf{9 8}$ & $\mathbf{9 9}$ & 479 & 192 & 118 & 1 & 1 & 1 & 1 & & 78 & \\
$\mathbf{1 0 0}$ & $\mathbf{1 0 1}$ & 634 & 34 & 31 & 1 & 1 & 1 & 1 & & 94 & \\
$\mathbf{1 0 2}$ & $\mathbf{1 0 2}$ & 650 & 650 & 188 & 1 & 1 & 2 & 2 & 54 & 83 & 47 \\
\hline $\mathbf{1 0 3}$ & $\mathbf{1 0 4}$ & 477 & 217 & 102 & 1 & 1 & 1 & 1 & & 81 & \\
$\mathbf{1 0 5}$ & $\mathbf{1 0 6}$ & 657 & 138 & 86 & 1 & 1 & 1 & 1 & 78 & 84 & 68 \\
\hline $\mathbf{1 0 7}$ & $\mathbf{1 0 8}$ & 615 & 263 & 143 & 1 & 1 & 1 & 1 & & 73 & \\
$\mathbf{1 0 9}$ & $\mathbf{1 1 0}$ & 617 & 79 & 66 & 1 & 1 & 1 & 1 & & 88 & \\
$\mathbf{1 1 1}$ & $\mathbf{1 1 2}$ & 659 & 280 & 164 & 1 & 1 & 1 & 1 & & 69 & \\
$\mathbf{1 1 3}$ & $\mathbf{1 1 4}$ & 657 & 22 & 21 & 1 & 1 & 1 & 1 & & 96 & \\
$\mathbf{1 1 5}$ & $\mathbf{1 1 2}$ & 617 & 280 & 163 & 1 & 1 & 1 & 1 & & 70 & \\
$\mathbf{1 1 6}$ & $\mathbf{1 1 7}$ & 615 & 109 & 86 & 1 & 1 & 1 & 1 & 36 & 84 & 25 \\
\hline $\mathbf{1 1 8}$ & $\mathbf{1 1 8}$ & 687 & 687 & 139 & 1 & 1 & 2 & 2 & & 87 & \\
$\mathbf{1 1 9}$ & $\mathbf{1 2 0}$ & 689 & 20 & 19 & 1 & 1 & 1 & 1 & 89 & 96 & 84 \\
\hline $\mathbf{1 2 1}$ & $\mathbf{1 1 2}$ & 379 & 280 & 132 & 1 & 1 & 1 & 1 & & 75 & \\
$\mathbf{1 2 2}$ & $\mathbf{1 2 3}$ & 376 & 304 & 135 & 1 & 1 & 1 & 1 & & 75 & \\
$\mathbf{1 2 4}$ & $\mathbf{1 2 5}$ & 403 & 133 & 90 & 1 & 1 & 1 & 1 & 74 & 83 & 47 \\
\hline $\mathbf{1 2 6}$ & $\mathbf{1 2 7}$ & 401 & 107 & 75 & 1 & 1 & 1 & 1 & & 86 & \\
$\mathbf{1 2 8}$ & $\mathbf{1 2 9}$ & 412 & 32 & 29 & 1 & 1 & 1 & 1 & & 95 & \\
$\mathbf{1 3 0}$ & $\mathbf{1 3 1}$ & 433 & 166 & 95 & 1 & 1 & 1 & 1 & 60 & 82 & 67 \\
\hline & & & & & 6 & & & & & \\
\hline
\end{tabular}

${ }^{a}$ molecular weight of molecule A. ${ }^{b}$ molecular weight of molecule B. ${ }^{c}$ adjusted reduced mass. ${ }^{d}$ number of reaction sites of molecule A. ${ }^{\mathrm{e}}$ number of reaction sites of molecule $\mathrm{B}$. ${ }^{\mathrm{f}}$ intermolecular reaction $=1$, intramolecular

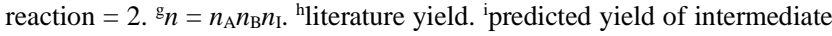
in each step. ${ }^{\mathrm{j}}$ predicted yield.
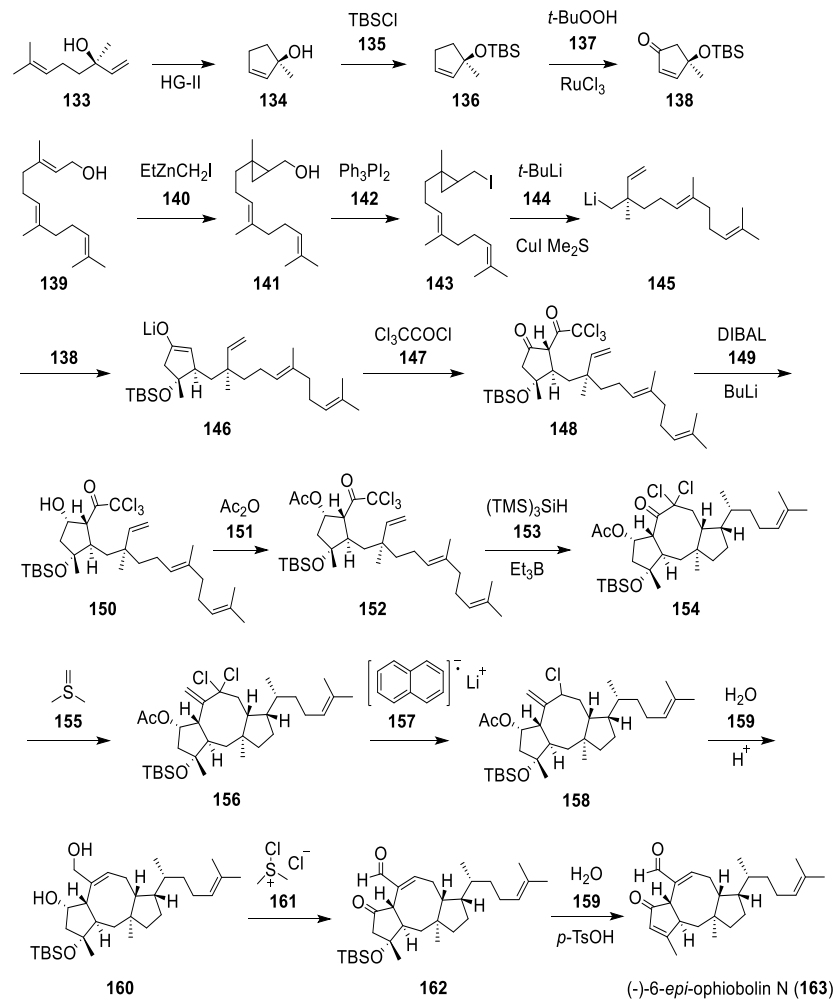

Scheme 6. Reaction scheme for analysis of reactions used in a total synthesis of (-)-6-epi-ophiobolin N, HG-II = HoveydaGrubbs' 2nd generation catalyst, TBS $=$ tert-butyldimethylsilyl, DIBAL = diisobutylaluminium hydride, Ac=acetyl, TMS = trimethylsilyl. 
Table 6. An analysis of reactions used in a total synthesis of (-)-6-epi-ophiobolin N.

\begin{tabular}{ccrrrrrrrrrr}
\hline $\mathrm{A}$ & \multicolumn{1}{c}{$\mathrm{B}$} & \multicolumn{1}{c}{$M_{\mathrm{A}}{ }^{\mathrm{a}}$} & $M_{\mathrm{B}}{ }^{\mathrm{b}}$ & $M_{\mathrm{AB}}{ }^{\mathrm{c}}$ & $n_{\mathrm{A}}{ }^{\mathrm{d}}$ & $n_{\mathrm{B}}{ }^{\mathrm{e}}$ & $n_{\mathrm{I}}^{\mathrm{f}}$ & $n^{\mathrm{g}}$ & $Y_{\text {lit. }}{ }^{\mathrm{h}}$ & $Y_{\text {int. }}{ }^{\mathrm{i}}$ & $Y_{\text {pred. }}{ }^{\mathrm{j}}$ \\
\hline $\mathbf{1 3 3}$ & $\mathbf{1 3 3}$ & 154 & 154 & 68 & 1 & 1 & 2 & 2 & & 94 & \\
$\mathbf{1 3 4}$ & $\mathbf{1 3 5}$ & 98 & 151 & 58 & 1 & 1 & 1 & 1 & & 89 & \\
$\mathbf{1 3 6}$ & $\mathbf{1 3 7}$ & 212 & 90 & 60 & 1 & 1 & 1 & 1 & 56 & 89 & 74 \\
\hline $\mathbf{1 3 9}$ & $\mathbf{1 4 0}$ & 222 & 235 & 99 & 1 & 1 & 1 & 1 & & 82 & \\
$\mathbf{1 4 1}$ & $\mathbf{1 4 2}$ & 236 & 516 & 136 & 1 & 1 & 1 & 1 & & 75 & \\
$\mathbf{1 4 3}$ & $\mathbf{1 4 4}$ & 346 & 64 & 51 & 1 & 1 & 1 & 1 & & 91 & \\
$\mathbf{1 4 5}$ & $\mathbf{1 3 8}$ & 226 & 226 & 97 & 1 & 1 & 1 & 1 & & 82 & \\
$\mathbf{1 4 6}$ & $\mathbf{1 4 7}$ & 453 & 182 & 114 & 1 & 1 & 1 & 1 & & 79 & \\
$\mathbf{1 4 8}$ & $\mathbf{1 4 9}$ & 592 & 142 & 97 & 1 & 1 & 1 & 1 & & 82 & \\
$\mathbf{1 5 0}$ & $\mathbf{1 5 1}$ & 594 & 102 & 78 & 1 & 1 & 1 & 1 & 28 & 86 & 25 \\
\hline $\mathbf{1 5 2}$ & $\mathbf{1 5 3}$ & 636 & 249 & 146 & 1 & 1 & 1 & 1 & 56 & 73 & 73 \\
\hline $\mathbf{1 5 4}$ & $\mathbf{1 5 5}$ & 602 & 76 & 63 & 1 & 1 & 1 & 1 & & 88 & \\
$\mathbf{1 5 6}$ & $\mathbf{1 5 7}$ & 600 & 135 & 98 & 1 & 1 & 1 & 1 & & 82 & \\
$\mathbf{1 5 8}$ & $\mathbf{1 5 9}$ & 565 & 18 & 17 & 1 & 1 & 1 & 1 & 46 & 97 & 70 \\
\hline $\mathbf{1 6 0}$ & $\mathbf{1 6 1}$ & 505 & 133 & 91 & 1 & 1 & 1 & 1 & & 83 & \\
$\mathbf{1 6 2}$ & $\mathbf{1 5 9}$ & 501 & 18 & 17 & 1 & 1 & 1 & 1 & 56 & 97 & 80 \\
\hline
\end{tabular}

${ }^{a}$ molecular weight of molecule A. ${ }^{b}$ molecular weight of molecule B. ${ }^{c}$ adjusted reduced mass. ${ }^{d}$ number of reaction sites of molecule A. ${ }^{\mathrm{e}}$ number of reaction sites of molecule B. intermolecular reaction $=1$, intramolecular reaction $=2 .{ }^{\mathrm{g}} n=n_{\mathrm{A}} n_{\mathrm{B}} n_{\mathrm{I}}$. ${ }^{\mathrm{h}}$ literature yield. ${ }^{\mathrm{i}}$ predicted yield of intermediate in each step. ${ }^{\mathrm{j}}$ predicted yield.

\section{References and Notes}

1 M. Kawashima, ChemRxiv. 2020, Preprint. https://doi.org/10. 26434/chemrxiv.12993218.v1

2 M. Kawashima, ChemRxiv. 2020, Preprint. https://doi.org/10. 26434/chemrxiv.13350974.v1

3 M. Kawashima, ChemRxiv. 2020, Preprint. https://doi.org/10. 26434/chemrxiv.13465718.v1

4 F. Yokokawa, H. Fujiwara, T. Shioiri, Tetrahedron Lett. 1999, 40, 1915.

5 D. F. Veber, S. R. Johnson, H.-Y. Cheng, B. R. Smith, K. W. Ward, K. D. Kopple, J. Med. Chem. 2002, 45, 2615.

6 I. Zemskov, S. Altaner, D. R. Dietrich, V. Wittmann, Org. Chem. 2017, 82, 3680.

7 L. Junk, U. Kazmaier, J. Org. Chem. 2019, 84, 2489.

8 X. Huang, L. Song, J. Xu, G. Zhu, B. Liu, Angew. Chem., Int. Ed. 2013, 52, 952.

9 S. Guo, J. Liu, D. Ma, Angew. Chem., Int. Ed. 2015, 54, 1298

10 Z. G. Brill, H. K. Grover, T. J. Maimone, Science 2016, 352, 1078.

11 Y. Chen, J. Zhao, S. Li, J. Xu, Nat. Prod. Rep. 2019, 36, 263.

12 A. Urosa, I. S. Marcos, D. Díez, G. B. Plata, J. M. Padrón, P. Basabe, Mol. Divers. 2016, 20, 369.

13 a) D. T. Hog, F. M. E. Huber, P. Mayer, D. Trauner, Angew. Chem., Int. Ed. 2014, 53, 8513. b) D. T. Hog, F. M. E. Huber, G. JiménezOsés, P. Mayer, K. N. Houk, D. Trauner, Chem. Eur. J. 2015, 21, 13646.

14 Molar heat capacity was calculated by MOPAC 6.0 with PM3 using Winmostar (V4, X-Ability Co. Ltd., Tokyo, Japan, 2012) as Gui interface. Reactions using Dess-Martin periodinane or 2iodoxybenzoic acid and reactions of compounds containing lithium elements out of the data in Tables 4 and 5 were excluded from the calculation. 